\title{
The delivery of primary school physical education in South African public schools: The perceptions of educators
}

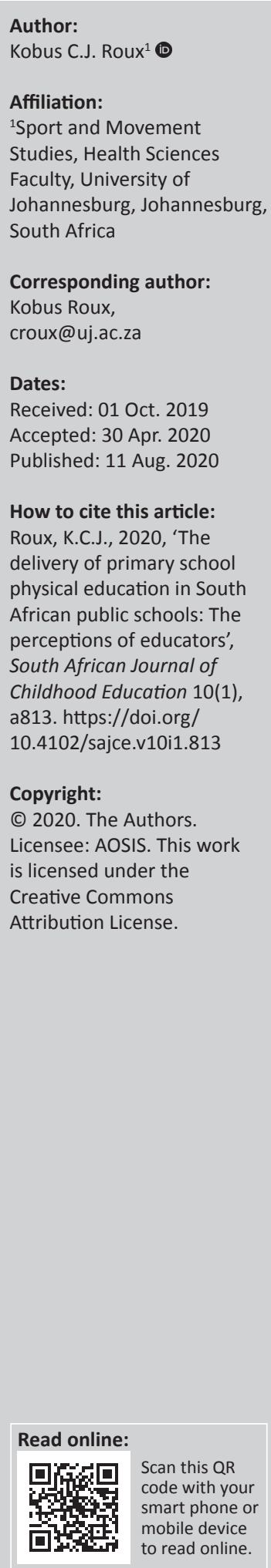

Background: Physical Education (PE) is a fundamental cornerstone for childhood development as it promotes lifelong participation in physical activities for holistic health. School educators play a key role in creating school environments that lead to developmentally appropriate and high-quality PE lessons.

Aim: The aim of this study was to determine educators' perceptions on the state and status of $\mathrm{PE}$ in selected public primary schools in all nine provinces of South Africa.

Setting: Data were collected on the campus of the selected primary schools within $150 \mathrm{~km}$ of a university. In the absence of a university within the stated radius, an airport was used as an initiated point of departure.

Methods: The mixed-methods approach (quantitative: questionnaires and qualitative: semistructured interviews and focus group discussions) was used to collect data. The purposive sampling method was used to select the participants. Quantitative data were analysed using descriptive statistics in the form of percentages, and presented using graphs and tables. Qualitative data were analysed using themes.

Results: The findings revealed that the educators from quintile 4 and 5 schools especially are of the opinion that challenges, such as a lack of resources, qualified PE specialist educators, and facilities and equipment negatively affected the delivery of PE at their schools.

Conclusion: Participants perceived that there are varying contextual and socio-economic school settings affecting the delivery of PE in the Curriculum Assessment Policy Statement (CAPS) curriculum. The researcher recommends that all learners have access to the adequate provision of PE programmes.

Keywords: educators; physical education; public primary schools; sport for development; Olympic studies.

\section{Introduction}

The World Health Organization (WHO) launched various campaigns and renewed its policy framework to address alarming worldwide mortality rates due to health conditions related to physical inactivity globally (WHO 2018). The South African public-school system faces severe challenges in delivering quality education to learners facing stark socio-economic realities daily. All learners have the right to meaningful learning experiences and opportunities in schools (Department of Basic Education [DBE] 2015). Physical Education (PE) consistently receives positive acclaim as a contributor to young learners' holistic development (cognitive, physical, social, affective and psychomotor) by promoting learners' physical activity (PA), especially in their formative years (Carse, Jess \& Keay 2017). Often the words 'physical education' and 'physical activity' are used interchangeably, yet they differ in important ways. Based on a sequence of learning, PE should not be compared with all kinds of PA experiences. Physical activity is defined as any bodily movement executed by skeletal muscles that requires energy expenditure, yet it should not be confused with merely doing exercises (WHO 2018). Activities such as working, playing, carrying out household chores and other recreational pursuits are all included. South Africa's 2018 Report Card on PA for children and youth shows that there is insufficient progress towards the promotion of safe and accessible physical activities for children. This stagnation is also compounded by the fact that participation in PE is below optimum standards (Draper et al. 2018). Most learning practices in primary schools involve learners 
spending significant amounts of time sitting at their desk, which adds to existing high sedentary lifestyle trends due to excessive technology and social media use amongst children (Donnelly, Mueller \& Gallahue 2017).

The reality in most public primary schools is that PE programmes are delivered by generalist teachers (Du Toit 2019). Physical education delivery, especially in the primary schools, is therefore a matter of vital concern. Effective PE delivery entails PE educators working towards presenting a comprehensive PE learning opportunity that, together with appropriate instruction, promotes quality theoretical and practical movement knowledge and skills (Lundvall 2015). In theSouth African context, educators are expected to competently plan and design PE learning programmes from relevant policies and a sequential and comprehensive curriculum, with the aid of relevant resources and the application of developmentally appropriate teaching methodologies (Department of Higher and Tertiary Education 2015).

In South Africa, PE underwent several policy-related restructurings, from being a stand-alone subject (prior to 1994) to Outcomes Based Education (Curriculum 2005, cited in Van Deventer 2011), resulting in the reduction of PE as one of the learning outcomes in Life Skills (LS) (Grades R-6) and Life Orientation (Grades 7-12). It requires that Human Movement and Development is implemented over four school phases, from the Foundation (Grades R-3), Intermediate (Grades 4-6) and Senior (Grades 7-9) to the Further Education and Training (Grades 10-12) phases (Stroebel, Hay \& Bloemhoff 2017; Van Deventer 2011). The ages of primary school learners range from 5 to 6 years in Grade R to 12 to 13 years in Grade 7. Without clear guidelines and models to afford a synergetic implementation (from theory to practice and meaningful outcomes), schools and educators followed a myriad of approaches, with some borrowing from international models, whilst others developed their own or kept to curriculumbased, activity- and assessment-focused implementation practices (Burnett 2018). The question 'What does PE look like in the public-school system?' became apparent.

Physical education focuses on addressing various social issues and is offered at schools with the aim of improving learner retention and academic performance (DBE 2017). Although PE and sport-related practices are not a panacea against entrenched social 'ills', there is evidence that it can contribute meaningfully to behavioural and lifestyle changes (Burnett 2018). Life Skills curricula, of which PE forms a negligible component, aim to contribute to installing positive social values and prosocial behaviours (Stroebel et al. 2016, 2019; Van Deventer 2011). Policy renewal, school infrastructure development, curricular reform, and stakeholder collaboration from global to local levels inform current national strategic drives (DBE 2017). The National Norms and Standards for school funding, according to the Department of Education (DOE 2004, cited in Van Wyk 2015), proposed the quintile rating system, ranked one to five. Quintile 1 is the group of schools catering for the poorest $20 \%$ of learners. Quintile 2 caters for the schools with the next poorest $20 \%$ of learners, and so on. At the other end of the scale, Quintile 5 schools are those schools that cater for the least poor $20 \%$ of learners. It is for the DOE to gauge the poverty levels and, therefore, the levels of funding required for all schools in all of the country's provinces. In the lower quintile schools, social issues have a spill-over effect due to low adult educational levels, alarming disease profiles related to inactivity and high unemployment (33.0\% in 2016 and $27.2 \%$ in 2018, with youth between the ages of 15 and 35 being at 38.2\%) (Mackay 2017:285; Statistics South Africa 2018; Van Wyk 2015). It is estimated that $13.5 \%$ of South African children aged 6-14 years are obese, which is higher than the global obesity prevalence of 10\% (Armstrong, Lambert \& Lambert 2011; Gupta et al. 2012).

Lynch and Soukop (2016) argue that such generalist educators usually lack the competency to teach PE. Given that the interest of primary school learners in play activities comes naturally to most of them, their generalist educators should undergo in-service training to design developmentally appropriate PE programmes with child-related features (Papageorgaki 2017). Given that primary school educators are nurturing and pastoral in their interface with learners, these attributes can promote amiable environments for PE learning (Collett 2013).

Physical Education should take place in an environment conducive to the learning and enriching of movement skills (such as stability, non- and locomotor and manipulative skills) (Stroebel et al. 2019). The health benefits of PA (Draper et al. 2018) include developing critical thinking skills and promoting the enjoyment of learning (Gallahue \& Donnelly 2003). Physical Education should therefore be developmentally and age-appropriate (Van Deventer 2011). In most South African school settings, the delivery of PE is treated as foundational to school sport programmes (Hollander 2017). The PE curriculum, however, is broader and physical literacy (Whitehead 2013) and the mastery of sport skills are building blocks for lifelong active living and continued sport participation (Kirk 2013). Often sport and PE are interchangeable, as some games and sport skills form part of the PE curriculum content (Burnett 2020). Many PE programmes therefore mainly consist of sports programmes, sometimes to the point at which schools make no conceptual distinctions between PE, PA and school sport (Gallahue \& Donnelly 2003). By capturing the interrelatedness of PE and school sport, the revised draft of the School Sport Policy for schools in South Africa, governed by the South African Schools Act, 1996 (Act 84 of 1996), states that 'school sport, which flows out of PE, provides the foundation for community and high-performance sport' (DBE 2017:7). Pope (2011) cites Murdoch's (1990) conceptual analysis of PE delivery in which he identifies five models of PE delivery in its relationship to school sport. These are the substitution, versus, reinforcement, sequential and integration models. The substitution model of delivery entails the interchangeable use of PE and school sport. This model is reinforced by public perception where, 
if one sees a PE class, they assume it is sports. The versus model provides a clear distinction between PE and sports and is manifested when schools have teachers who are dedicated to PE, and sports managers who are distinctly dedicated to intra- and inter-school sports activities (Pope 2011). The reinforcement model of delivery identifies the reciprocal link between PE and school sport. Its underpinning philosophy is that PE and school sport can co-exist in a collaborative framework (Pope 2011). The sequence model is premised on the view that PE prepares learners for school sport and, therefore, implies that PE classes should be a talent pool for school sport (Pope 2011). The integration model is a multi-sector and multi-stakeholder-centred approach which recognises that PE delivery calls for liaison and cooperation amongst various stakeholders within and outside the school (Michael et al. 2015). Considering the various schools of thought on PE delivery in its relationship to school sport, scholars such as Van Deventer (2015) and Whitehead (2013) call for PE delivery that is inclusive for all learners. An ideal PE delivery leads to the development of physical literacy, which is not centred exclusively on unwholesome competitions that often exclude less gifted learners (Van Deventer 2015; Whitehead 2013). Often more focus is on those activities which have aspects of speed and physical intensity, at the expense of activities with dimensions of aesthetics and rhythm (Mattsson \& Lundvall 2013).The main factors which influence the delivery of PE in schools are school philosophies on PE, the availability of resources such as facilities and personnel and wider national policies on PE.

The South African Department of Higher Education and Training regards an educator as an individual who provides and delivers educational services and support to learners at school (Department of Higher Education and Training 2015). This study mainly focused on principals, Heads of Department (HODs) and LS teachers who are also responsible for PE, according to the Curriculum Assessment Policy Statements (CAPS) curriculum. These key persons are strategically poised in their respective roles to advance the $\mathrm{PE}$ agenda by shaping the direction and development of schools as well as the quality of teaching and learning in PE delivery (DBE 2015). In the context of primary schools, the learners' natural physiological and psychological responses to movement stimuli are highly favourable. This means that PE lessons can result in optimal and holistic development as well as a positive movement culture in children (Pienaar \& Kemp 2014).

\section{Vygotsky's socio-interaction theory}

An ideal educational environment should equip learners with holistic competences which promote physical, cognitive, social and emotional learning for effective engagement with the 'real' world (Carse et al. 2017). Learning settings are social contexts in which educators interact with learners for knowledge construction and dissemination (Rolymos 2018). The Vygotsky socio-interaction theory places high emphasis on the role of context in influencing the learning process in schools (Vygotsky 1978). In applying this theory to PE delivery, PE educators form a key part of the PE contextual environment in schools. Principals, HODs and teachers mediate PE delivery in schools; consequently, their views are vital to understanding the PE situation in schools (Foot 2014). Amongst other responsibilities, educators are responsible for ensuring PE delivery through effective teaching, fair resource allocation, impartial time allocation, authentic assessment and continuous professional development for effective interpersonal interactions and knowledge construction in schools (Ho et al. 2016).

\section{Problem statement}

The evolvement of PE from being a stand-alone subject to its current status as an appendage of LS is well documented in South African scholarship (Burnett 2018; Stroebel et al. 2016, 2017, 2019; Van Deventer 2014). The changes in the curriculum, which included outcomes-based education and the revised National Curriculum Statement (NCS) (up to the current NCS Grades R-12) were not easy for educators to adjust to (Stroebel et al. 2019). These adjustments compromised the pedagogical structure by allocating to it the least time in the curriculum (DBE 2011). However, socioeconomic inequality affects the majority of South Africans, with $87.7 \%$ of public schools constituting no-fee schools which accommodated $77.2 \%$ of the total school population in 2015 (Ndebele 2017:483). As a result, PE practices in South Africa cannot be assumed to be homogenous. It is therefore critical to explore nuances on the delivery of PE in public schools. A national assessment on PE delivery can result in multi-dimensional perspectives which can inform policy and lead to contextually relevant interventions (Amusa \& Toriola 2010). The CAPS curriculum identifies educators as key support structures in implementing inclusive, diversified and well-managed PE programmes (DBE 2011). The question is: What does PE look like in the primary public-school system? For clarity, it is critical to explore the views of educators on the delivery of PE in schools.

\section{Aim and objectives}

The aim of this paper is to reflect on the perceptions of educators on the state and status of PE in all public primary school types in South Africa. These aims are broken down into the following objectives:

- To explore the views of educators on the state and status of PE in South African public primary schools.

- To determine perceived factors which may have an impact on the delivery of PE in public primary schools.

- To collect data from selected public primary schools representing differing geographical contexts (rural, semiurban and urban) and their socio-economic status from all nine provinces.

\section{Methodology}

After in-depth consultation with key representatives from the DBE and the United Nations Children's Fund (UNICEF) 
South Africa, a national research project was conducted across all of the South African provinces to determine the state and status of PE in public schools. The study was conducted under the banner of South African Universities Physical Education Association (SAUPEA). This article forms part of and emanates from this project.

\section{Research design}

The study adopted the mixed-methods research approach involving the use of qualitative and quantitative methods. Qualitative data were collected using semi-structured interviews with principals and HODs to gain information on policies and decision-making in LS and PE. With teachers, focus group discussions were conducted to gain information on content and delivery of PE programmes. Quantitative data were collected using questionnaires. Questionnaires included different sections, structured to first obtain biographical data (which included the professional qualifications and experiences of teachers), followed by perceptions and experiences of PE (implementation and 'uptake'), the identification of good practices, challenges and recommendations. For teachers, a Likert scale delivered nuanced responses compared to that of learners who had two categorical options ('agree' or 'disagree'). Open responses for recommendations for educators contributed to prioritised views and the identification of real needs. This approach also allows for the triangulation of results from the combination of both qualitative and quantitative methods to reveal the complex reality of multiple understandings where data intersect (Creswell 2013).

\section{Research participants}

The participants in this study consisted of a cohort of principals, HODs and LS teachers responsible for PE in selected South African public primary schools. These participants were drawn from selected quintile 1-3 schools in rural and township areas, and quintile $4-5$ schools in urban areas.

\section{Sampling}

The purposive sampling method was used in the selection of participants. Principals, HODs and LS teachers were purposively selected with the mindset that they were key informants with relevant experiences concerning the research topic under investigation, and would therefore provide critical perspectives on the state and status of PF in South African public primary schools. Only participants who signed consent forms participated in the study. The participating schools were selected based on being located within a $150 \mathrm{~km}$ radius of a university. In the absence of a university within the stated radius, an airport was used as an initiated point of departure.

\section{Validity and reliability}

This study used semi-structured interviews and focus group discussions (qualitative data) and questionnaires (quantitative data) to collect information from the participants. In the qualitative data, trustworthiness was ascertained through credibility, confirmability and dependability criteria. The credibility criteria used in this study involved the keeping of notes on research decisions made, the coding of data, and the use of member checking to verify and validate findings. The confirmability and dependability criteria involved keeping records of the research path throughout the study from the development to the reporting of the findings. Raw data from the semi-structured interviews and the focus group discussions were transcribed verbatim for verification.

\section{Research procedure and ethical clearance}

After obtaining ethical clearance (REC-01-131-2016) from the Faculty of Health Sciences, University of Johannesburg, and access to schools from the DBE, a pilot study was conducted and the necessary changes to the instruments were done. Co-ed public primary schools were selected from rural $(n=$ $1)$, semi-urban $(n=1)$ and urban $(n=1)$ areas in and around Johannesburg to participate in the pilot study. These schools were excluded from the final study.

On arrival at the various schools, quantitative data (questionnaires) and qualitative data (interviews, focus group discussions) protocols were followed. With the support of the principal, a coordinator (in all cases the HOD for LS) was appointed to streamline the data collection process regarding the venue and time slot for the various activities. The questionnaire, which was successfully administered in previous research (Burnett \& Hollander 2007), was adopted and, accordingly, necessary validity and reliability required for the study was guaranteed.

Interviews were conducted with the principal and HODs regarding decision-making in PE. These semi-structured interviews resulted in viewpoints which offered context through explanations of existing policy frameworks as well as insight into the current curriculum implementation.

The focus group discussions with selected teachers $(n=6 ; 3=$ male, 3 = female per school) followed the same design as the questionnaires but enabled the collection of narrative data, for the researcher to contextualise explanations of the empirical data obtained through the questionnaires. The study's ethical considerations included informed consent, voluntary participation, the right to privacy, confidentiality anonymity and protection from any harm. No disruption of lesson time was allowed and, therefore, data collection occurred during break and lunch times.

\section{Data analysis}

Quantitative data were analysed using descriptive statistics (frequencies and percentages) using the Statistical Package for the Social Sciences (SPSS version 21). These were presented using tables and graphs. After all responses from semi-structured interviews and focus group discussions were transcribed verbatim, qualitative data were analysed 
using themes and sub-themes. The line by line coding method was used to generate interrelated concepts and statements. The emerging patterns were then analysed and synthesised to address the main aim of the study, which was to determine educators' perspectives on the state and status of PE in South African public primary schools.

\section{Ethical considerations}

Ethical approval was received from the Faculty of Health Sciences Ethics Committee, University of Johannesburg, REC-01-131-2016.

\section{Results}

\section{Participating schools and respondents}

Figure 1 presents the number of schools that participated in the study per province. A total of 34 primary schools participated in the study. The North West province had the highest number of schools participating in the study (26\%). The Limpopo province recorded the least number of schools that participated in the study. The low response in the Limpopo province was the result of the absence of quintile 4 and 5 schools within a $150 \mathrm{~km}$ radius of the University of Venda, the chosen point of departure for the study.

Figure 2 presents the quintile rankings of the schools that participated in the study. The highest number of schools were in quintile $5(32 \%)$ and were followed by schools in quintile 4 (24\%). The lowest number of schools were special needs schools (3\%). However, results for special needs schools are not included in this study as they are reported on a different platform.

Table 1 presents the research participants who participated in the study, the data collection techniques and the research instruments used to collect information from the respondents. The highest number of participants consisted of LS teachers $(n=102)$. Principals participated in semi-structured interviews and data were collected using an interview schedule. Heads of Department participated in semi-structured interviews and questionnaires. Data were collected using an interview schedule and a questionnaire. Life Skills teachers participated in focus group discussions and questionnaires.

Figure 3 shows that most HODs (67.3\%) and teachers (47.2\%) have 5 or more years of experience in the field of PE.

Figure 4 presents findings on LS teachers' responses on PE activities offered in the schools. Most responses (69.9\%) indicated that PE comprised structured PE. These were followed by sport activities and fitness activities, with outdoor adventure having the least number of responses.

Table 2 presents the categories of implementers who offer $\mathrm{PE}$ in schools per quintile. The findings show that in quintile 1 schools, most of the PE implementers were class teachers (generalists). In quintile 2 and 3 schools, a significant number of PE implementers were class educators. Specialists

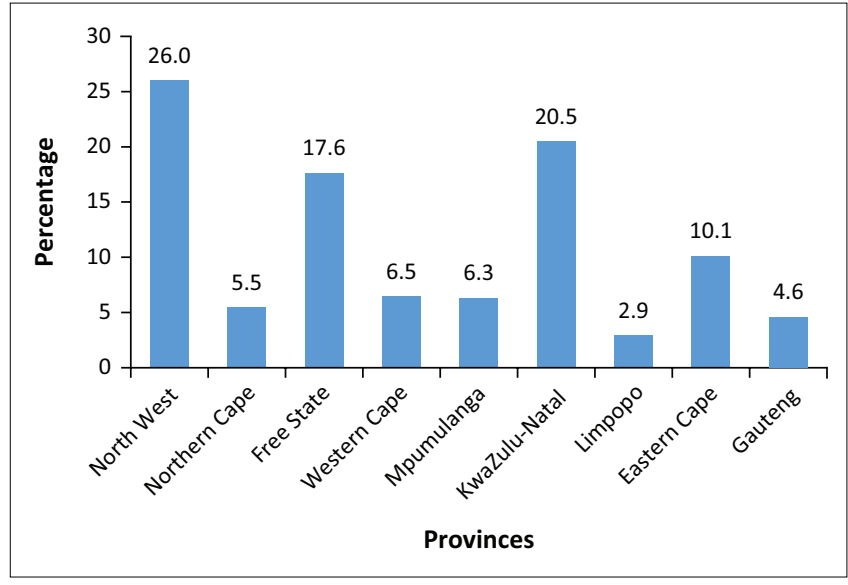

Source: Adapted from Burnett, C., 2018, State and status of physical education in public schools of South Africa: National research report, UNICEF, Pretoria

FIGURE 1: Participating primary schools per province.

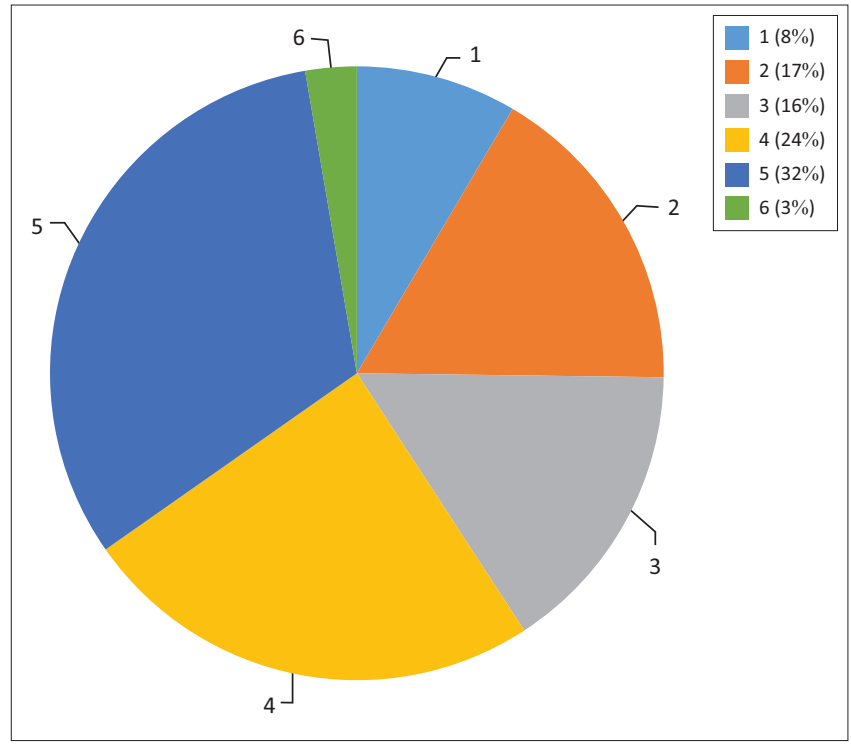

Source: Adapted from Burnett, C., 2018, State and status of physical education in public schools of South Africa: National research report, UNICEF, Pretoria

FIGURE 2: Participating primary schools per quintile.

TABLE 1: Research participants.

\begin{tabular}{lll}
\hline Participant & Data collection technique & Data collection instrument \\
\hline Principal $(n=34)$ & Semi-structured interview & $\begin{array}{l}\text { Interview schedule } \\
\text { Audio tape recorder } \\
\text { Notepad }\end{array}$ \\
& & Interview schedule \\
HOD $(n=27)$ & Semi-structured interview & Audio tape recorder \\
& Questionnaire & Notepad \\
& & Questionnaire \\
Teacher $(n=102)$ & Focus group discussion & Focus group schedule \\
& & Audio tape recorder \\
& Questionnaire & Notepad \\
& & Questionnaire \\
\hline
\end{tabular}

HOD, Head of Department.

and external implementers were also involved in PE. In quintile 4 and 5 schools, a significant number of $\mathrm{PE}$ implementers were class educators and specialists. External and 'other' providers were also involved in PE implementation. External providers consisted of nongovernmental organisations (NGOs) and franchised 
movement programmes such as Monkeynastix and Playball. The 'other' providers mainly consisted of sport coaches and members of staff who were not necessarily teachers but offered their services voluntarily to help in PE activities.

Figure 5 presents comparative findings between HODs and LS teachers' perceptions on the challenges that they face in the implementation of PE. On aspects such as access to facilities, the availability of equipment, the quality of equipment and the quality of facilities, most, or both, HODs and teachers indicated that this was a significant problem.

\section{Principals' perspectives on physical education implementation}

During interviews, principals indicated that schools strove to abide by the necessary policies and governance structures for the teaching of PE. Principals also highlighted the value and significance of PE. The key benefit was in the potential of PE to

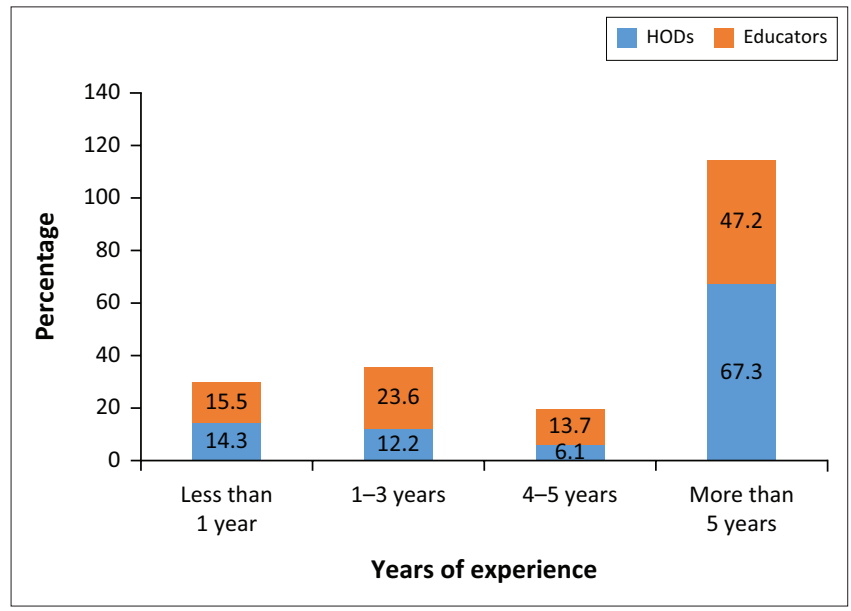

Source: Adapted from Burnett, C., 2018, State and status of physical education in public schools of South Africa: National research report, UNICEF, Pretoria

HODs, Heads of Department.

FIGURE 3: Heads of Department and teachers' years of experience in teaching physical education. help promote social, cognitive and psychological health and identify sport talent. Respondents highlighted the following:

'It's very important as it is about the health of the learners. They say a healthy mind in a healthy body. Obesity is a problem in South Africa'. (Female, 53 years old, higher quintile school)

'We need to exercise to keep fit. So, I think it's of importance not only for learners but also for educators'. (Male, 49 years old, lower quintile school)

'In [the] Olympics we do not perform well as a country because the problem starts at the grassroots in primary schools. Some learners have potential, but PE is not taken seriously. We should produce many sportsmen and sportswomen'. (Male, 38 years old, lower quintile school)

However, some challenges had a negative effect on the implementation of PE. These challenges were captured in responses such as the following:

'We don't have open places e.g. a soccer field. We need to have space where we can [do] ... physical training. Another thing is [that] most of the materials are not enough because our enrolment is big'. (Female, 50 years old, lower quintile school)

'For me and my staff, the over-assessment driven expectation with the limited activities provided by CAPS, as well as the theory-practice discrepancy and time allocation are a huge challenge'. (Female, 57 years old, higher quintile school)

'Sometimes you find that the circuit gives us 20 instead of 50 books. Our school is situated in a rural area. Children depend on social security grants. Our school is situated near shebeens where they play loud music and disturb children'. (Male, 55 years old, lower quintile school)

TABLE 2: Presenters who implement physical education per school type.

\begin{tabular}{llll}
\hline PE presenters & $\begin{array}{l}\text { Quintile } \mathbf{1} \\
\text { schools }\end{array}$ & $\begin{array}{l}\text { Quintile } \mathbf{2} \text { and } \mathbf{3} \\
\text { schools }\end{array}$ & $\begin{array}{l}\text { Quintile } \mathbf{4} \text { and } \mathbf{5} \\
\text { schools }\end{array}$ \\
\hline $\begin{array}{l}\text { Class teachers } \\
\text { (generalists) }\end{array}$ & Highly available & Highly available & Highly available \\
PE specialist teachers & Not available & Available & Highly available \\
External providers & Not available & Available & Available \\
Other & Available & Available & Available \\
\hline
\end{tabular}

$\mathrm{PE}$, physical education.

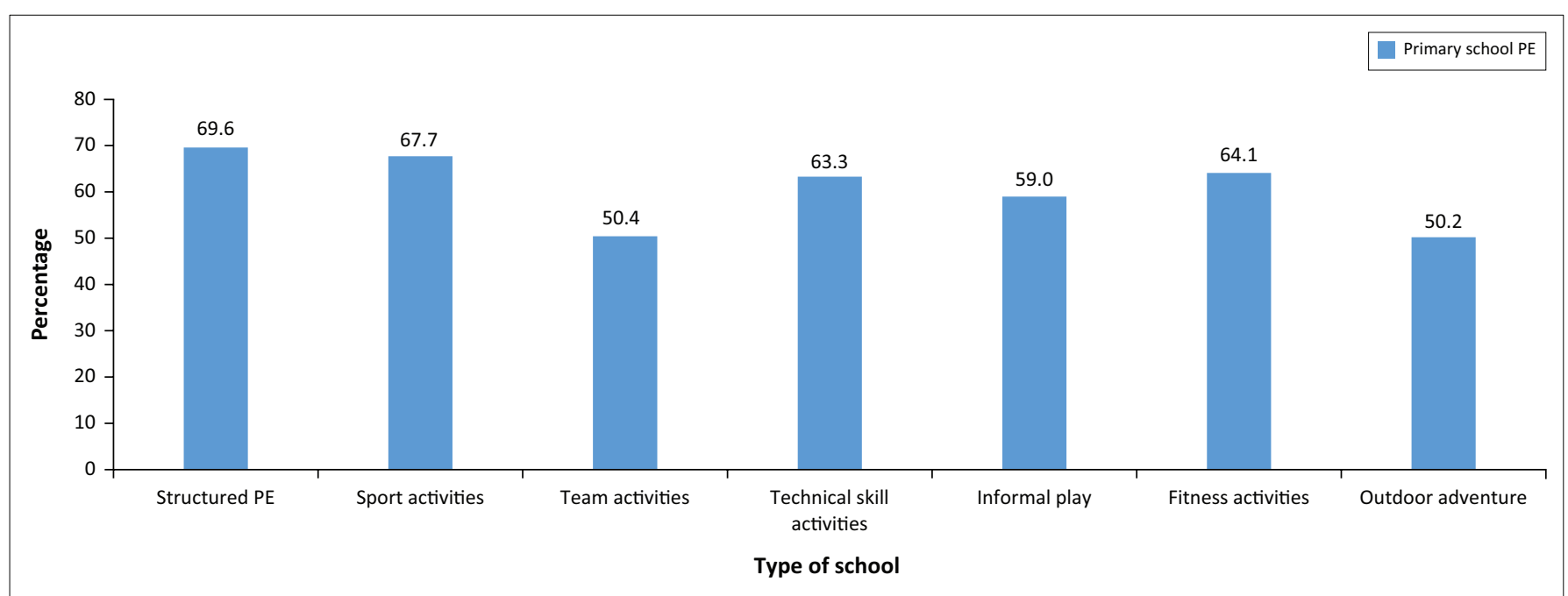

Source: Adapted from Burnett, C., 2018, State and status of physical education in public schools of South Africa: National research report, UNICEF, Pretoria $\mathrm{PE}$, physical education.

FIGURE 4: Physical education activities offered in schools. 


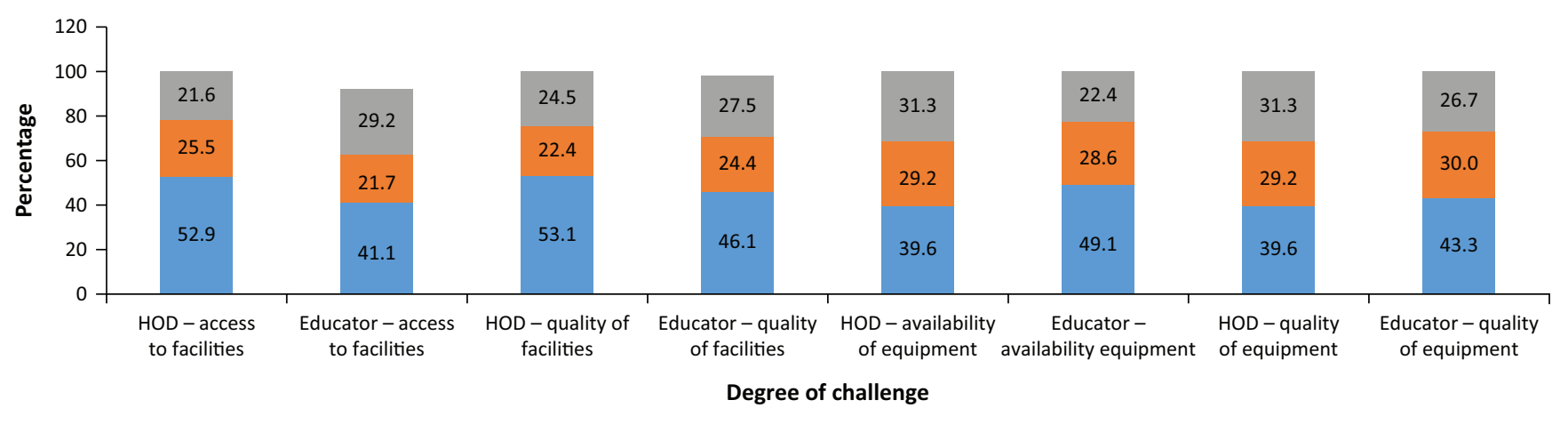

Source: Adapted from Burnett, C., 2018, State and status of physical education in public schools of South Africa: National research report, UNICEF, Pretoria HODs, Heads of Department.

FIGURE 5: Perceived challenges in implementing physical education.

Despite some of the challenges, some principals indicated that they worked with various external stakeholders to make up for the shortcomings within the school. Some principals indicated the following:

'We are fortunate in our community. We invite people from the community who come freely. A retiree who was good in shotput and javelin volunteered. Some of our learners proceeded to provincial level due to his assistance. So, some people are willing from outside to come and assist or donate'. (Female, 48 years old, higher quintile school)

'A gentleman from our community often visits our school to teach our learners sport skills such as soccer and even netball'. (Male, 55 years old, lower quintile school)

\section{Perspectives of Heads of Department on physical education implementation}

Heads of Department agree, with relatively more of them being negative, on teachers being able to cope with the workload $(24 \%)$, being equipped to teach PE $(27.5 \%)$ or being in physical shape to do so $(23.5 \%)$. At the time of the research, only $32(65.3 \%)$ of HODs taught PE, which may pose a challenge in terms of them being optimally informed of teacher performances or being able to provide adequate leadership and mentorship for inexperienced and inadequately trained educators. Although as educators, both cohorts are positive about the educational value and possible benefits of $\mathrm{PE}$, responses from HODs indicated that although PE was an important subject in schools, there were some key challenges which needed to be addressed. Some HODs highlighted the following:

'PE is an important subject because it provides learners with the opportunity to play and exert [themselves] physically. In that regard, education cannot be said to be complete without $\mathrm{PE}^{\prime}$. (Female, 43 years old, higher quintile school)

'PE provides options for learners to discover their talents'. (Male, 40 years old, lower quintile school)

'Through PE, a learner can develop to be one of the big athletes or soccer players in South Africa. So, it's important because sport is one of the careers that learners can pursue'. (Female, 34 years old, higher quintile school)
The key challenges that were highlighted by HODs on the delivery of PE were time constraints, attitudinal problems, unwholesome teaching practices by some teachers and a lack of teaching materials. Some of the key responses were:

'The time for PE is very small. So sometimes teachers find it very difficult to complete the whole PE syllabus. So, I think it must be given more time in the curriculum. So, these are some of the things that the Department of Basic Education should look into'. (Female, 31 years old, lower quintile school)

'I think some teachers believe that PE is not very important. So, they try to replace it on the timetable with other subjects, homework or just free play'. (Male, 40 years old, lower quintile school)

'I try by all means to make sure that our teachers teach PE according to the timetable'. (Male, 37 years old, higher quintile school)

'PE is a very important subject in my view. We just need more materials and support from curriculum advisors to implement it effectively in my schools. Our advisors do not understand the need and benefits of PE. Sometimes we struggle to follow what the CAPS curriculum requires us to do because the teaching materials are not enough. Too much emphasis is put on assessment, yet we do not have enough time to teach and to do proper assessment'. (Male, 35 years old, lower quintile school)

\section{Teachers' perspectives on physical education implementation}

Most teachers indicated that they are positive, that PE is a valuable subject, and they expressed their willingness to teach the learning area, especially PE. Some teachers indicated, during several focus groups, that they are less positive due to a heavy workload and 'too frequent assessment and lots of administration' which leaves them with 'little time to teach'.

Some of the gleaned key responses included:

'I regard PE to be effective in preventing the onset of diseases such as obesity in children. It is therefore a very important subject in schools'. (Focus group, male, higher quintile school)

'The number of learners is too much. It is difficult to manage the learners especially when they are doing physical activities and demonstrations. I am not able to properly monitor and assess what other learners will be doing'. (Focus group, female, lower quintile school) 
'We do not have proper equipment, facilities or space for PE. We just have a small dusty open ground which is full of stones. We also do not have enough balls. So, the number of activities we do in PE are very limited'. (Focus group, female, lower quintile school)

'Most learners love PE and they enjoy it. This makes it easier to facilitate lessons. Some of the learners have a negative attitude but I try to motivate them'. (Focus group, male, higher quintile school)

'I need to go for workshops. I am not yet competent myself. I have not received anything in terms of staff development ever since I came here. Other subject teachers other than PE go for workshops, but PE teachers do not'. (Focus group, female, lower quintile school)

\section{Discussion}

\section{Perceived benefits of physical education}

The findings showed that the educators held a favourable view of PE in the selected primary schools. They particularly cited health and sport talent identification as the main benefits of participating in PE. These findings correspond with views by Bailey, Cope and Parnell (2015) who cite the holistic benefits of $\mathrm{PE}$ as being physical, social and emotional. However, an awareness of the benefits of PE does not always translate appropriate teaching practices into achieving these outcomes. The status of PE in schools is very low as educators often emphasise the importance of other subjects, such as mathematics and sciences (Van Deventer 2011). Findings in this study revealed that educators often only allowed their learners to participate in PE and do the necessary assessments required by the curriculum out a sense of duty.

\section{Physical resources}

The findings in this study showed that there was a pervasive lack of facilities and equipment in the schools. The United Nations Educational, Scientific and Cultural Organization (UNESCO 2015) mandates schools to provide quality PE through the availability of suitable and quality facilities and equipment. The findings of this study correspond with Crum (2012) and Hardman et al. (2014) that the shortage of PE resources in schools is a classic example of how policy rhetoric on PE does not correspond with practice in schools. Accordingly, PE continues to endure a peripheral and marginal status in curricular priorities (Van Deventer 2011).

\section{The nature of physical education delivery}

Physical education activities mainly comprised sport activities, physical fitness activities and informal play. According to Stidder and Hayes (2017) as well as McDavid, Cox and Amorose (2017), diversifying PE programmes can motivate learners as a result of the multiple learning options that are offered. The findings revealed that there were nuances across quintiles on the adults responsible for delivering PE. The differences could be explained in terms of the quintile differences of the schools. Quintile 1 schools are usually rural and township schools, which are the poorest (Van Wyk 2015).
In such schools' surrounding contexts, social issues (because of high unemployment), low educational levels and high disease burdens related to inactivity are prevalent (Burnett 2018). In this study, it was revealed that these schools had no specialist PE teacher. The majority were generalist teachers who, by extension, could be classified as untrained to expertly teach PE. Petrie (2010) argues that generalist teachers normally lack the self-assurance to teach PE because of their nonspecialised training in PE.

However, quintile 4 and 5 schools enjoy a relatively high percentage of specialist teachers compared to the lower quintile schools (Van Wyk 2015). The presence of specialist PE teachers in these schools augurs well for quality pedagogical practices in PE teaching and learning. Specialist teachers are perceived to be confident and competent in their delivery of $\mathrm{PE}$ as a result of their specialised training and preparation (Petrie 2010). Anecdotally, the presence of specialist teachers in higher quintile schools and their absence in lower quintile schools can be argued to be a reflection of how historical socio-economic inequalities still continue to feature in the provision of PE in the South African education system (Burnett 2018). The presence of multiple stakeholders in PE delivery in higher quintile schools is consistent with Pope's (2011) call for an integrated and multi-sector approach to PE delivery, which recognises that liaison and cooperation amongst various stakeholders, within and outside the school, is key to the delivery of quality PE programmes (Michael et al. 2015). To generate some degree of bridging the inequality gap between lower quintile and higher quintile schools, continuous professional development for low quintile generalist teachers is important to connect them to new ideas and current best practices in PE teaching (Shehu 2009).

\section{The interface between educators' perspectives and the South African policy framework for physical education}

The Constitution of South Africa, 1996 (Act 108 of 1996) is the overarching document which governs all institutional, policy and legislative frameworks. Maharajh, Nkosi and Mkhize (2016) are of the view that curricular practices in schools, including the provision of $\mathrm{PE}$, should reflect equality and justice, in line with the spirit of the constitution. In this study, educators' perspectives point towards the importance of PE and its benefits for primary school learners. However, the importance of PE on paper is not matched by practical steps in terms of resources. The South African Schools Act, 1996 (Act 84 of 1996) provides that the state must fund public schools from public revenue on an equitable basis, enabling learners to exercise their right to education. It also calls for the redress of past inequalities in education provision. The perceived lack of specialist teachers, especially in the lower quintile schools compared to the historically privileged higher quintile schools, is reflected in this study. Since the 1999 Berlin Worldwide Summit drew mandates to globally improve PE in schools (Hardman \& Green 2011), it seems that educators are of the sentiment that more should be done to improve the PE situation in schools. 


\section{Recommendations from educators}

Participants highlighted their key recommendations to improve PE delivery in schools. The key emerging recommendations included improved physical resources through building new facilities and upgrading existing ones. They also highlighted the need to train educators on PE teaching and the use and maintenance of facilities. Such a call is consistent with the Department of Higher Education's call for a teacher to be knowledgeable about the school curriculum, unpack its specialised content, use available resources appropriately and design suitable learning programmes (Department of Higher Education and Training 2015).

\section{Conclusion and recommendations}

This study reveals that educators perceive significant challenges regarding PE implementation, especially in low quintile schools. However, best practices such as collaborations with various external stakeholders, such as NGOs and knowledgeable community members, can help to alleviate some of the challenges that schools face in providing PE.

Teachers are most pivotal for good practices, but it is clear that lower quintile schools especially are severely restricted by a lack of resources, and an often hostile or unsupportive environment in these schools. These foster an academically biased ideology and culture, focusing on the avoidance of 'social ills' rather than on positive and holistic development. There are ample examples of best practices, such as collaborations with various external stakeholders (e.g. NGOs and knowledgeable community members) that can assist to alleviate some of the challenges these schools face in teaching PE. Well-trained and motivated teachers are effective and most valuable in ensuring meaningful PE practices and, as such, can convincingly overcome multiple challenges.

This study recommends that educators, especially the teachers, must be comprehensively consulted on key decisions that affect PE, as their views carry influence on the delivery of $\mathrm{PE}$ in schools. The study further recommends the forging of educator partnerships between schools and other institutions that are well-resourced and schools that are ill-equipped to facilitate the sharing of resources. Further studies on PE should explore ways in which educators can be equipped to innovatively improve PE delivery through improvisation, strategic school-community partnerships and resource mobilisation.

\section{Acknowledgements}

The author would like to thank the researchers of the South African University Physical Education Association (SAUPEA) in their national research project: State and status of physical education in public schools of South Africa.

\section{Competing interests}

The author declares that no competing interests exist.

\section{Author's contributions}

C.J.R. is the sole author of this article.

\section{Funding information}

Funding was received from United Nations Children's Fund (UNICEF) and was acknowledged.

\section{Data availability statement}

Data sharing is not applicable to this article as no new data were created or analysed in this study.

\section{Disclaimer}

The views and opinions expressed in this article are those of the author and do not necessarily reflect the official policy of any affiliated agency of the author.

\section{References}

Amusa, L.O. \& Toriola, A.L., 2010, 'The changing phases of physical education and sport in Africa: Can a uniquely African model emerge?', African Journal for Physical, Health Education, Recreation and Dance 16(4), 666-680.

Armstrong, M.E.G., Lambert, E.V. \& Lambert, M.I., 2011, 'Physical fitness of South African primary school children, 6 to 13 years of age', 'Discovery Vitality Health of the Nation Study'. Perceptual and Motor Skills 113(3), 999-1016.

Bailey, R., Cope, E. \& Parnell, D., 2015, 'Realising the benefits of sports and physical activity: The human capital model', Federación Española de Asociaciones de docentes de Educación Física (Spanish Federation Association for the Teaching of Physical Education) 28, 147-154

Burnett, C. \& Hollander, W.J., 2007, 'The sport-in-development impact assessment tool (S.DIAT)', African Journal for Physical Health, Education, Recreation and Dance, Special Edition, June 2007, 123-135.

Burnett, C., 2018, State and status of physical education in public schools of South Africa: National research report, UNICEF, Pretoria.

Burnett, C., 2020, State and status of school sport in public schools of South Africa: National research report, University of Johannesburg, Johannesburg.

Carse, N., Jess, M. \& Keay, J., 2017, 'Primary physical education: Shifting perspectives to move forwards', European Physical Education Review, 24(4), 1-16. https://doi.org/ 10.4324/9781315545257-17

Cleland-Donnelly, F.E., Mueller, S.S. \& Gallahue, D., 2017, Developmental physical education for all children, 5th edn., Human Kinetics, Champaign, IL.

Collett, K.S., 2013, 'Teacher perceptions of the role of a primary school principal in supporting their well-being: Learning from a South African public school in challenging conditions', Doctoral thesis, University of the Western Cape, Cape Thawn.
Town

Creswell, J.W., 2013, Qualitative inquiry and research design, SAGE, Thousand Oaks, CA.

Crum, B., 2012, 'How to pave the road to a better future for physical education', Journal of Physical Education \& Health 2(3), 53-64.

Department of Basic Education (DBE), 2011, Department of Basic Education National Curriculum Statement: Curriculum and Assessment Policy Statement. Life Skills Intermediate Phase Grades 4-6, Government Printer, Pretoria.

Department of Basic Education (DBE), 2015, Policy on the South African Standard for Principalship, Department of Basic Education, Pretoria.

Department of Basic Education \& Sport and Recreation South Africa, 2017, Memorandum of understanding, viewed 25 May 2020, from https://www.srsa. gov.za/media/joint-statement-signing-mou-between-srsa-and-dbe-improvegov.za/media/joi
school-sports.

Department of Higher Education and Training, 2015, National Qualifications Framework Act, 2008 (Act 67 of 2008). Revised policy on the minimum requirements for teacher education qualifications, Government printer, Pretoria.

Draper, C.E., Tomaz, S.A., Bassett, S.H., Burnett, C., Christie, C.J., Cozett, C. et al., 2018 'Results from South Africa's 2018 Report Card on physical activity for children and youth', Journal of Physical Activity and Health 15(suppl 2), 406-408. https://doi. org/10.1123/jpah.2018-0517

Du Toit, D., 2019, 'Service-learning within field experience of physical education teacher education in South Africa: Experiences of pre-service and in-service teachers', South African Journal for Research in Sport, Physical Education and Recreation 41(1), 13-29.

Foot, K., 2014, 'Cultural-historical activity theory: Exploring a theory to inform practice and research', Journal of Human Behavior in the Social Environment 24(3), 329-347. https://doi.org/10.1080/10911359.2013.831011

Gallahue, D.L. \& Cleland, C.F., 2003, Developmental physical education for all children, 4th edn., Human Kinetics, Champaign, IL. 
Gupta, N., Goel, K., Shah, P. \& Misra, A., 2012, 'Childhood obesity in developing countries: Epidemiology, determinants and prevention', Endocrine Reviews 33(1), 48-70. https://doi.org/10.1210/er.2010-0028

Hardman, K. \& Green, K., 2011, Contemporary issues in physical education: International perspectives, Meyer \& Meyer Sport, Maidenhead, UK.

Hardman, K., Murphy, A., Routen, A. \& Tones, S., 2014, UNESCO-NWCPEA: World-wide survey of school physical education; final report, UNESCO Publishing, Paris.

Ho, W.K.Y., Ahmed, M.D., Wong, B., Huang, F., De D’Amico, R., Dinold, M. et al., 2016 'Quality physical education and global concern - Ways ahead and future development', Revista Electrónica Actividad Física y Ciencias (Electronic Journal of Physical Activity and Science) 8(1), 60-70.

Hollander, W., 2017, 'Delivering physical education in selected schools in Soweto, South Africa: Soweto Active Schools programme', African Journal for Physical Activity and Health Sciences 23(1:2), 204-214.

Kirk, D., 2013, 'Educational value and models-based practice in physical education', Educational Philosophy and Theory 45(9), 973-986. https://doi.org/10.1080/001 31857.2013.785352

Lynch, T. \& Soukup, G.J., 2016, "“Physical education", "health and physical education", "physical literacy" and "health literacy": Global nomenclature confusion" Cogent Education 3(1), 1217820. https://doi.org/10.1080/2331186X.2016. 1217820

Maharajh, L.R., Nkosi, T. \& Mkize, M.C., 2016, 'Teachers' experiences of the implementation of the Curriculum and Assessment Policy Statement (CAPS) in three primary schools in KwaZulu Natal', Africa's Public Service Delivery \& Performance Review 4(3), 371-389. https://doi.org/10.4102/apsdpr.v4i3.120

Mackay, G., 2017, 'Employment', in F. Cronje \& T. Ndebele (eds.), South Africa survey 2017, pp. 233-330, South African Institute of Race Relations, Johannesburg.

McDavid, L., Cox, A.E. \& Amorose, A.J., 2017, 'The relative roles of physical education teachers and parents in adolescents' leisure-time physical activity motivation and behavior', Psychology of Sport and Exercise 13(2), 99-107. https://doi.org/ 10.1016/j.psychsport.2011.10.003

Mattsson, T. \& Lundvall, S. 2013. The position of dance in physical education. Sport, Education and Society, 20(7), 1-17.

Michael, S.L., Merlo, C.L., Basch, C.E., Wentzel, K.R. \& Wechsler, H., 2015, 'Critical connections: Health and academics', Journal of School Health 85(11), 740-758. https://doi.org/10.1111/josh.12309

Murdoch, E.B., 1990, 'Physical education and sport: The interface', in N. Armstrong (ed.), New directions in physical education, pp. 63-78, Human Kinetics, Champaign, IL.

Ndebele, T., 2017, 'Education', in F. Cronje \& T. Ndebele (eds.), South Africa survey 2017, pp. 459-580, South African Institute of Race Relations, Johannesburg.

Papageorgaki, Z.K., 2017, 'Researching the lived experience of physical education: Some pedagogical insights', Sport, Education and Society 23(9), 916-927. https:// doi.org/10.1080/13573322.2017.1278586

Petrie, K., 2010, 'Creating confident, motivated teachers of physical education in primary schools', European Physical Education Review 16(1), 47-64. https://doi.org/ $10.1177 / 1356336 \times 10369200$
Pienaar, A.E. \& Kemp, C., 2014, 'Motor proficiency profile of Grade 1 learners in the North-West province of South Africa: NW-child study', South African Journal for Research in Sport, Physical Education and Recreation 36(1), 167-182.

Pope, C.C., 2011, 'The physical education and sport interface: Models, maxims and maelstrom', European Physical Education Review 17(3), 273-285. https://doi.org/ $10.1177 / 1356336 \times 11416728$

Rolymos, S., 2018, 'Knowledge and identities: The relation between professional identities and PCK (pedagogical content knowledge)', Doctoral thesis, North-West University, Potchefstroom.

Shehu, J., 2009, 'Peer provocation in physical education: Experiences of Botswana adolescents', Educational Studies 35(2), 143-152. https://doi.org/10.1080/ 03055690802470324

Statistics South Africa, 2018, Youth unemployment still high in Q1: 2018, viewed 10 October 2018, from https://www.statssa.gov.za/?p=11129

Stidder, G. \& Hayes, S. (eds.), 2017, The really useful physical education book, 2nd edn., Routledge, New York, NY.

Stroebel, L.C.E., Hay, J. \& Bloemhoff, H., 2016, 'Physical education in South Africa: Have we come full circle?', South African Journal for Research in Sport, Physical Education and Recreation 38(3), 215-228.

Stroebel, L.C.E., Hay, J. \& Bloemhoff, H., 2017, 'Needs and challenges of Foundation Phase life skills teachers in delivering physical education: Jack of all trades and master of none?', South African Journal for Research in Sport, Physical Education and Recreation 39(3), 163-177.

Stroebel, L.C.E., Hay, J. \& Bloemhoff, H., 2019, 'An approach to re-skilling of in-service teachers in physical education in South African schools', South African Journal of Education 39(2), 1-12. https://doi.org/10.15700/saje.v39n2a1643

United Nations Educational, Scientific and Cultural Organisation (UNESCO), 2015, Quality physical education (QPE): Guidelines for policy-makers, UNESCO, Paris.

Van Deventer, K.J., 2011, 'The state and status of physical education in selected primary schools in four South African provinces: A survey', African Journal for Physical, Health Education, Recreation and Dance 17(4), 823-840.

Van Deventer, K.J., 2014, 'Educational worth of physical education and sport participation: A review', South African Journal for Research in Sport, Physical Education and Recreation 36(3), 183-200.

Van Deventer, K.J., 2015, 'The voice of Margaret Talbot on physical education and school sport: A tribute', South African Journal for Research in Sport, Physical Education and Recreation 37(2), 143-157.

Van Wyk, B., 2015, Research design and methods part 1: Post-graduate enrolment and throughput, University of the Western Cape, viewed 09 August 2014, from https:// www.uwc.ac.za/Students/Postgraduate/Documents/Research_and_Design_I.pdf

Vygotsky, L.S., 1978, Mind in society: The development of higher psychological processes. Harvard University Press, Cambridge, MA.

Whitehead, M, 2013, 'What is the education in physical education?' in S. Capel \& M. Whitehead (eds.), Debates in physical education, pp. 22-36, Routledge, Oxon, UK.

World Health Organization (WHO), 2018, Physical inactivity: A global public health problem, viewed10October 2018, from https://www.who.int/dietphysicalactivity/ factsheet_inactivity/en/ 